\title{
Melanoma-associated mutants within the serine-rich domain of PAK5 direct kinase activity to mitogenic pathways
}

\author{
Kyle M. LaPak ${ }^{1}$, Dennis C. Vroom ${ }^{1}$, Ayush A. Garg², Xiangnan Guan ${ }^{1}$, John L. Hays ${ }^{3}$, \\ Jonathan W. Song ${ }^{2}$ and Christin E. Burd ${ }^{1,4}$ \\ ${ }^{1}$ Department of Molecular Genetics, The Ohio State University, Columbus, OH, USA \\ ${ }^{2}$ Department of Mechanical and Aerospace Engineering, The Ohio State University, Columbus, OH, USA \\ ${ }^{3}$ Division of Medical Oncology, Department of Internal Medicine, The Ohio State University, Columbus, OH, USA \\ 4 Department of Cancer Biology and Genetics, The Ohio State University, Columbus, OH, USA \\ Correspondence to: Christin E. Burd, email: burd.25@osu.edu
}

Keywords: PAK7; PKA; melanoma; melanocyte; p21-activated kinase

Received: April 01, $2018 \quad$ Accepted: April 26, $2018 \quad$ Published: May 22, 2018

Copyright: LaPak et al. This is an open-access article distributed under the terms of the Creative Commons Attribution License 3.0 (CC BY 3.0), which permits unrestricted use, distribution, and reproduction in any medium, provided the original author and source are credited.

\section{ABSTRACT}

The overexpression and hyperactivity of p21-activated serine/threonine kinases (PAKs) is known to facilitate tumorigenesis; however, the contribution of cancerassociated $P A K$ mutations to tumor initiation and progression remains unclear. Here, we identify p21-activated serine/threonine kinase 5 (PAK5) as the most frequently altered PAK family member in human melanoma. More than $60 \%$ of melanomaassociated PAK5 gene alterations are missense mutations, and distribution of these variants throughout the protein coding sequence make it difficult to distinguish oncogenic drivers from passengers. To address this issue, we stably introduced the five most common melanoma-associated PAK5 missense mutations into human immortalized primary melanocytes (hMELTs). While expression of these mutants did not promote single-cell migration or induce temozolomide resistance, a subset of variants drove aberrant melanocyte proliferation. These mitogenic mutants, PAK5 S364L and D421N, clustered within an unstructured, serine-rich domain of the protein and inappropriately activated ERK and PKA through kinase-independent and -dependent mechanisms, respectively. Together, our findings establish the ability of mutant PAK5 to enhance PKA and MAPK signaling in melanocytes and localize the engagement of mitogenic pathways to a serine-rich region of PAK5.

\section{INTRODUCTION}

Alterations in $B R A F, N R A S$, and NF1 define the canonical genetic subtypes of melanoma, yet each of these oncogenic mutations is insufficient to drive tumorigenesis [1]. Only a fraction of BRAF- or NRASmutant melanocytes form tumors in genetically engineered mouse models, and benign human nevi harboring these oncogenic lesions rarely progress to form tumors [2-10]. Drugs targeting alterations in $B R A F, N R A S$, or $N F 1$ are either unavailable or fail to elicit durable responses [1116]. Thus, there is an ongoing need to elucidate new, therapeutically tractable genetic alterations prevalent in melanoma. Unfortunately, efforts to identify such targets have been hindered by the inordinate number of somatic gene variants in human melanomas [1, 17-19]. Here, we define the oncogenic potential of common missense mutations in the p21-activated kinase (PAK) family of serine/threonine kinases, revealing new insights relevant to the therapeutic targeting of these proteins in melanoma and other tumor types.

PAKs are classified into two groups based upon peptide sequence homology [20]. Group I PAKs (PAK1, 2, and 3) contain an N-terminal p21 binding domain (PBD) which mediates interactions with Rho family GTPases such as RHO, RAC, and CDC42 [21-23]. Binding of Rho family members to the PAK PBD promotes kinase activity by alleviating inhibitory, intermolecular interactions 
between the PAK N-terminal autoinhibitory (AID) and C-terminal kinase domains [21-23]. Mechanism governing the kinase activity of group II PAKs (PAK4, 5/7, 6) are still under investigation, with two distinct regulatory models proposed. In the first model, derived from studies of PAK4 purified from mammalian cells, N-terminal CDC42 binding is sufficient to displace the group II AID and stimulate kinase activation [24]. However, in the second model, based upon experiments employing mammalian PAK4 isolated from bacteria, it is suggested that maximal catalytic activity is achieved only when CDC42 engagement is accompanied by binding of $\mathrm{SH} 3$ domaincontaining proteins to an $\mathrm{N}$-terminal pseudosubstrate domain present in group II PAKs [25]. Once activated, all PAKs phosphorylate a myriad of downstream targets, but can also exhibit kinase-independent scaffolding functions that enhance cellular signal transduction. For instance, PAK1 facilitates the interaction of proteins within the MAPK and PI3K/AKT cascades, leading to increased activation of these pathways [26-32]. While reports of such kinase-independent functions are common for group I PAKs, similar activities have yet to be fully explored in group II PAKs.

PAKs control many cellular processes implicated in cancer initiation and progression, including: cytoskeletal remodeling, cell survival, and proliferation [33]. Alterations that increase PAK levels, such as genomic amplification or mRNA/protein overexpression, occur frequently in cancer and contribute to tumor progression [33]. For example, PAKI amplification drives the anchorage-independent growth of breast cancer cell lines, while duplications of $P A K 1$ and 4 correlate with poor outcomes in patients with ovarian cancer [34-36]. Elevated PAK1 protein levels are associated with colorectal, hepatocellular, and prostate cancer metastasis, and PAK2 and 6 overexpression is linked to chemotherapeutic and radiation resistance in breast and prostate cancers, respectively [37-42]. These findings have stimulated interest in developing ATP-competitive compounds to limit PAK kinase activity; yet, the development of specific inhibitors has been impeded by the large and flexible PAK catalytic pocket [43]. The only PAK inhibitor to reach a phase I clinical trials failed due to low oral bioavailability, high toxicity, and minimal tumor responses $[43,44]$.

Few studies have investigated the role of PAKs in melanoma. These limited reports in melanoma cell lines and mouse models, associate enhanced PAK1 and 4 activity with aberrant proliferation, invasion, and therapeutic resistance [45-48]. Heightened PAK1 signaling is also associated with aquired resistance to single-agent BRAF inhibitor and dual-agent BRAF/MEK inhibitor therapies $[49,50]$. Such work establishes a role for heightened $P A K$ activity in melanoma progression and therapeutic resistance, yet studies investigating the oncogenic potential of PAK missense mutations are lacking. Here, we elucidate mechanisms by which common $P A K$ missense mutations drive inappropriate melanocyte proliferation, revealing functional insights relevant to the formulation of drugs to target PAKs in cancer.

\section{RESULTS}

\section{$P A K 5$ is the most frequently altered $P A K$ family member in human melanoma}

Using cBioportal, we examined the alteration status of all six $P A K$ genes in a dataset of 287 melanoma samples curated by The Cancer Genome Atlas (TCGA) Research Network [51, 52]. Within these samples, PAK5 alterations were nearly twice as frequent as those observed in other $P A K$ family members (21\% versus $6-11 \%$; Figure 1A). This enrichment was unique to melanoma, as PAK5 alterations were infrequent in other TCGA-analyzed tumor types ( $<9 \%$; Supplementary Figure 1A). Most melanomaassociated PAK5 alterations were missense mutations $(62 \%)$, localized throughout the protein coding sequence within both the PBD and kinase domain as well as uncharacterized regions (Figure 1A, 1B). We investigated the co-occurrence of PAK5 alterations with the three most common melanoma drivers: BRAF, NRAS, and NF1. While $P A K 5$ alterations were randomly distributed across both $B R A F$ - and $N R A S$-mutant melanomas ( $p=0.20$ and 0.30 , respectively), these alterations were significantly enriched in NF1-mutant tumors ( $p=0.01$; Supplementary Figure 1B, 1C). PAK5 alterations did not co-occur with other group II $P A K S$, but instead, coincided with alterations in $P A K 3$ ( $p=0.02$; Figures 1A, Supplementary Figure 1D). Taken together, these data show that PAK5 is the most frequently mutated $P A K$ in human melanoma.

\section{Melanoma-common $P A K 5$ mutations do not alter PAK5 kinase activity}

PAK5 missense mutations are evenly distributed throughout characterized and uncharacterized domains of the protein, making it difficult to predict the functional consequences of these alterations in melanoma (Figure 1B). Therefore, we selected the five most frequently observed PAK5 mutants in our dataset for further analysis: E144K, M173I, E294K, S364L, and D421N (Figures 1B, 2A; blue dots). A kinase-dead PAK5 mutant (K478/9R, $\mathrm{KD}$ ) and a constitutive active PAK5 mutant (S573N, CA) were included as controls in our experiments (Figure 2A; red and green dots, respectively) [24, 53]. FLAG-tagged versions of these mutant proteins were stably expressed in human primary immortalized melanocytes (hMELTs) under the control of a $U b C$ promoter. FLAG-PAK5 expression was consistent amongst the stable cell lines except for PAK5 CA, which displayed $\sim 30 \%$ lower protein 
levels (Figure 2B). We also observed that PAK5 CA migrated at a higher molecular weight, presumably due to protein post-translational modifications (Figure 2B).

Pre-clinical therapeutics target PAK kinase activity [43]. To determine if common melanomaassociated PAK5 mutations affect enzymatic function, we immunoprecipitated individual PAK5 mutants from our hMELT stable cell lines and subjected these proteins to in vitro kinase assays using a canonical PAK4 peptide substrate [54]. As expected, PAK5 KD displayed dramatically reduced kinase activity, while PAK5 CA increased peptide phosphorylation $>20$-fold over wildtype PAK5 (Figure 2C). Kinase activity of the melanomaassociated PAK5 mutants, E144K, M173I, E294K, S364L, and D421N, was similar to the wildtype control (Figure 2C). These data demonstrate that the protein products of melanoma-common PAK5 missense mutations do not exhibit altered kinase activity.

\section{Single-cell melanocyte migration and temozolomide resistance are unchanged by the expression of melanoma-common PAK5 mutants}

PAK proteins regulate a variety of cytoskeletal remodeling processes critical for tumor migration and invasion [55]. To examine the impact of PAK5 mutations on melanocyte migration, we used time-lapse microscopy and measured the motility of our hMELT stable cell lines across a microfluidics device (Figure 3A, Supplemental Movie). This microfluidics assay provides several advantages over traditional measures, such as Boyden chamber or scratch assays. The device allows for the simultaneous tracking of bi-directional cell velocity and migratory persistence. Furthermore, confounding survival or proliferation differences are eliminated because data is only acquired from viable, non-dividing cells. To conduct this assay, we seeded our hMELT stable cell lines under full serum conditions into the central port of the device. The following day, cells within the seeding port were starved of growth factors, while full serum media was kept in the flanking collection ports. After 36 hours, images were taken at five minute intervals over a 12 hour period and stitched together using ImageJ. We measured the velocity and directional persistence of single cells migrating through the device channels. hMELT cell lines harboring wildtype or mutant PAK5 exhibited a similar velocity; however, expression of PAK5 CA stimulated a marginal increase in migratory speed $(p=0.1$; Figure 3B). The directional persistence of PAK5-mutant hMELTs was also unchanged in comparison to cells harboring wildtype PAK5, but trended towards significance in both

A

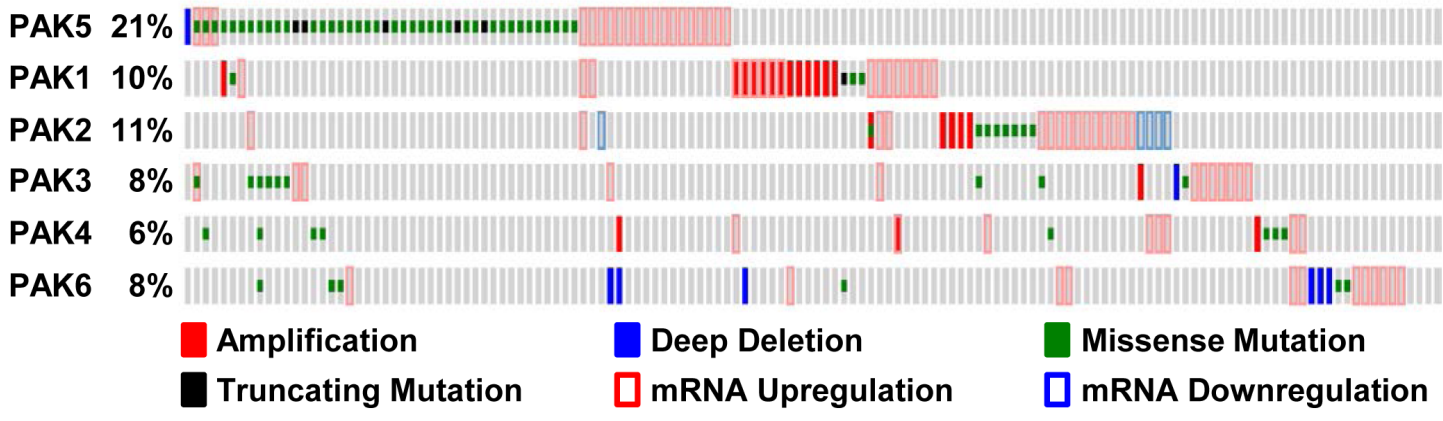

B

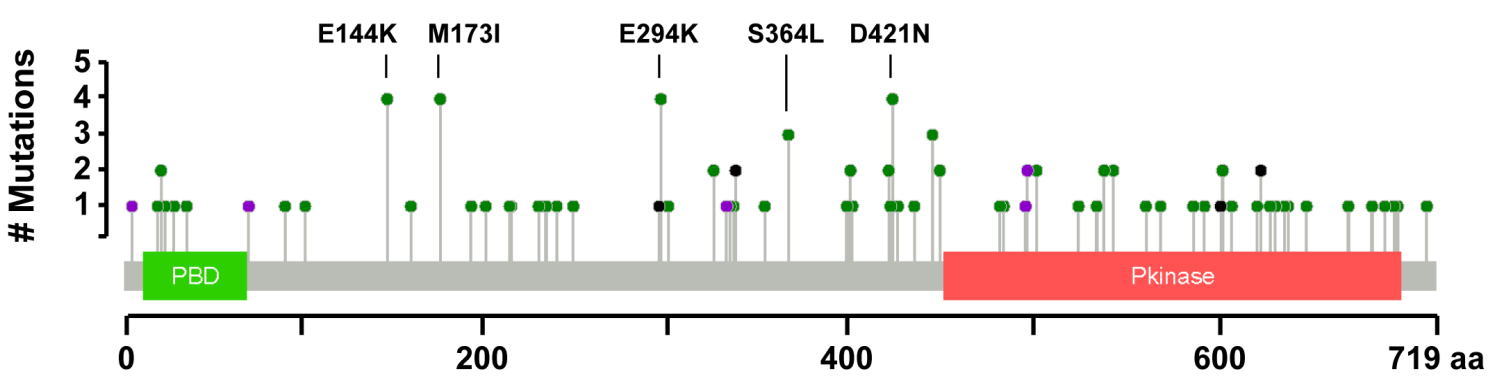

Figure 1: PAK5 is the most frequently altered PAK family member in melanoma. A. Oncoprint generated in cBioPortal depicting alterations in the PAK gene family for 287 melanomas collected by TCGA (provisional data accessed on 08/2016). PAKs are divided into two groups based upon protein sequence homology: group I (PAK1, PAK2 and PAK3) and group II (PAK4, PAK5, and PAK6). B. Protein diagram of human PAK5 depicting the location and frequency of melanoma-associated variants. Green dots represent missense mutations, black dots represent truncating mutations, and purple dots represent splice-site mutations. 
the PAK5 CA and PAK5 E144K-expressing cell lines $(p=0.1$; Figure $3 \mathrm{C})$. These data show that common, melanoma-associated PAK5 mutants do not drastically change the single-cell migratory velocity or persistence of immortalized melanocytes.

Exogenous expression of wildtype PAK5 was shown to increase apoptotic resistance in $\mathrm{CHO}$ cells treated with camptothecin or C2-ceramide [56]. To determine whether melanoma-common PAK5 mutants confer resistance to temozolomide, an alkylating chemotherapeutic drug approved for the treatment of malignant melanoma [57], we first ascertained the $\mathrm{IC}_{50}$ of temozolomide in hMELT cells expressing wildtype PAK5 (250 $\mu \mathrm{M}$; Figure 3D). The viability of our hMELT stable lines was assessed after seven days of treatment with $250 \mu \mathrm{M}$ temozolomide using both resazurin metabolism and direct cell counts (Figure $3 \mathrm{E}$, data not shown). While the expression of melanomacommon PAK5 mutants had no effect on temozolomidetreated cells, evidence of resistance was observed in melanocytes harboring PAK5 CA ( $p=0.01$; Figure $3 \mathrm{E})$.

\section{PAK5 S364L and D421N enhance melanocyte proliferation}

In addition to cellular migration and apoptotic resistance, PAKs are frequently implicated in proliferative control [58]. Therefore, we examined the effect of each PAK5 mutant on melanocyte proliferation. We seeded our hMELT stable cell lines at 40-50\% confluence. The next day, the cells were placed in media containing $2 \%$ serum. After 18 hours, these cultures were pulsed with EdU for eight hours to monitor cellular proliferation Using flow cytometry to quantify EdU incorporation, we found that cells harboring PAK5 CA displayed increased proliferation, while those containing the PAK5 KD showed decreased EdU incorporation, as compared to wildtype PAK5 (Figure 4A). Notably, two of the melanoma-associated mutants, S364L and D421N, promoted melanocyte proliferation $(87 \%$ and $89 \%$ increase, respectively; Figure 4A). A modest increase in proliferation was also observed with PAK5 M173I; however, this increase did not reach statistical significance in subsequent assays (See Figures 4A, 5B, 6B).

PAK1, 3, and 5 are reported to interact directly with CRAF and/or MEK to stimulate growth factorindependent proliferation [1, 59-64]. To examine MAPK signaling in our hMELT stable cell lines, we first assessed the phosphorylation status of the RAF homologs, BRAF and CRAF. Levels of BRAF-pS445 remained unchanged in all the hMELT stable cell lines (Figures 4B). In contrast, CRAF-pS338 increased moderately in PAK5 S364L and D421N-expressing melanocytes $(p=0.1, p=0.2$, respectively; Figure $4 C$ ). Because there was little change in RAF activation, we investigated downstream MAPK targets. Increases in MEK activation were highly variable in hMELT cells stably expressing PAK5 S364L or D421N and did not reach statistical significance $(p=0.1$; Figure 4D). However, a more striking phenotype was observed downstream of MEK, where expression of either PAK5 S364L and D421N nearly doubled ERK-pT202/204 levels in comparison to the wildtype control $(p=0.005$ and $p$ $=0.04$, respectively; Figure 4E). Together, these data correlate ERK activation with the enhanced proliferation seen in hMELT cells expressing PAK5 S364L or D421N.

\section{PAK5 S364L and D421N promote melanocyte proliferation dependent on kinase activity}

PAK1 is reported to activate MAPK signaling through both kinase-dependent and -independent mechanisms [32, 59-61]. Therefore, we generated hMELT stable cell lines harboring kinase-dead (K478/9R; KD) versions of the PAK5 M173I, S364L, and D421N mutants, and confirmed the expression and catalytic deficiency of these proteins (Supplementary Figure 2A, 2B). Stable expression of PAK5 S364L-KD or D421N-KD increased pERK-T202/Y204 levels nearly two-fold over wildtype PAK5 (Figure 5A), recapitulating the phenotype of the kinase-proficient mutants. However, expression of PAK5 S364L-KD or D421N-KD did not enhance melanocyte proliferation as measured by EdU incorporation, suggesting that hMELT cells are insensitive to ERKmediated mitogenic signals (Figure 5B). Indeed, treatment of parental and PAK5-expressing hMELT cells with a selective MEK inhibitor, trametinib, completely abolished ERK activity in these cells without altering cellular proliferation (Figure 5C). These data demonstrate that although PAK5 S364L-KD and D421N-KD enhance ERK activity in a kinase dependent manner, this mechanism is not responsible for the increased mitogenic activity of select PAK5 mutants in hMELT cells.

\section{Activation of PKA by PAK5 S364L and D421N promotes proliferation}

The finding that hMELT cells grow in a MAPKindependent manner was not surprising. hMELTs are immortalized with both hTERT and CDK $4^{\mathrm{R} 24 \mathrm{C}}$, and prior studies establish the ability of constitutive CDK4/Cyclin D1 activity to drive MAPK-independent melanoma growth [65-67]. However, because the p16-CDK4/6$\mathrm{Rb}$ axis is deregulated in $\sim 70 \%$ of melanomas [1], our hMELT stable lines provided an excellent backdrop for the discovery of clinically relevant pathways engaged by mitogenic PAK5 mutants. We began by examining the WNT and cAMP pathways which, in addition to the MAPK pathway, are critical regulators of melanocyte proliferation [68]. PAK5 wildtype, S364L, and D421N expressing cells displayed similar levels of intracellular cAMP and showed no change in total or phosphorylated 


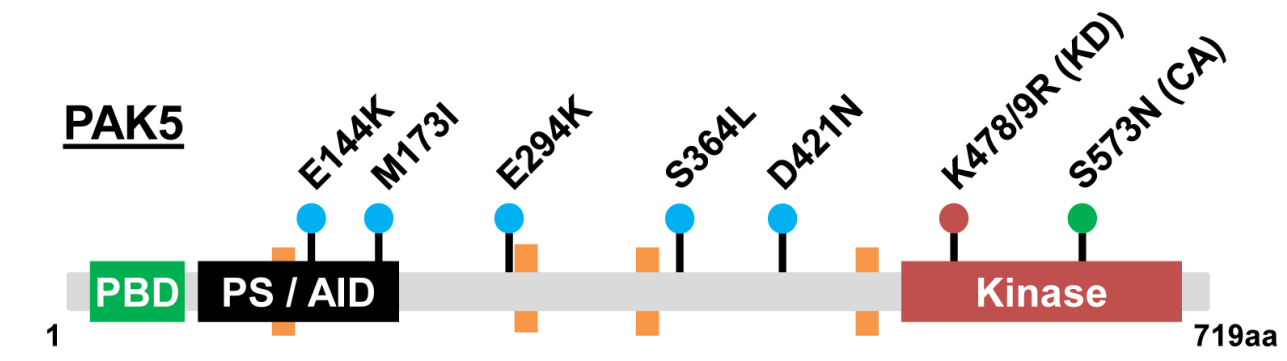

B

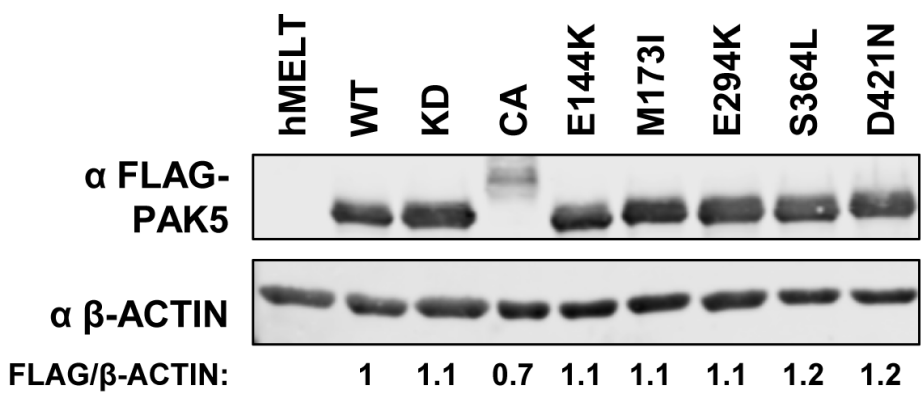

C

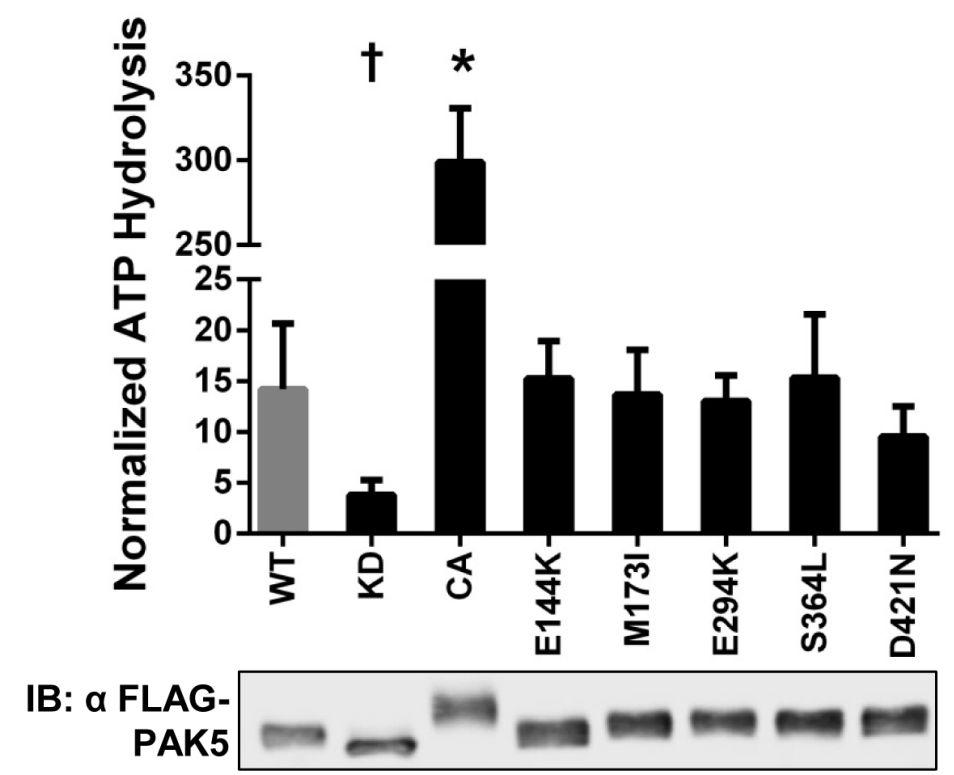

IP: FLAG

Figure 2: Melanoma-common PAK5 mutants do not alter kinase activity. A. Protein diagram depicting the location of human PAK5 variants examined in this study. Dots are color-coordinated to divide the mutations into groups: the most frequent melanoma variants (E144K, M173I, E294K, S364L and D421N) in blue, a kinase dead mutant (K478/9R, KD) in red, and a constitutive active mutant $(\mathrm{S} 573 \mathrm{~N}, \mathrm{CA})$ in green. $\mathrm{PBD}=\mathrm{p} 21$-binding domain, $\mathrm{PS} / \mathrm{AID}=$ pseudosubstrate/auto-inhibitory domain, Kinase = kinase domain. Orange boxes represent proline-rich motifs (PxxP). B. Immunoblot showing the stable expression of FLAG-tagged PAK5 variants in immortalized human primary melanocytes (hMELTs). 'hMELT' indicates the parental cell line. Shown below each lane is the $\beta$-ACTIN-normalized level of mutant PAK5 expression relative to PAK5 wildtype (WT). C. PAK5 kinase activity was measured using the ADP-Glo system and normalized to immunoprecipitated protein levels as measured by immunoblot. A representative immunoblot of immunoprecipitated FLAGPAK5 is shown. Each bar represents three biological replicates with the mean and standard deviation indicated. $\uparrow=p<0.05, *=p<0.001$ compared to PAK5 WT (gray bar), where $p$-values were calculated using multiple t-tests and significance determined by FDR $(\mathrm{Q}=5 \%)$. 
A

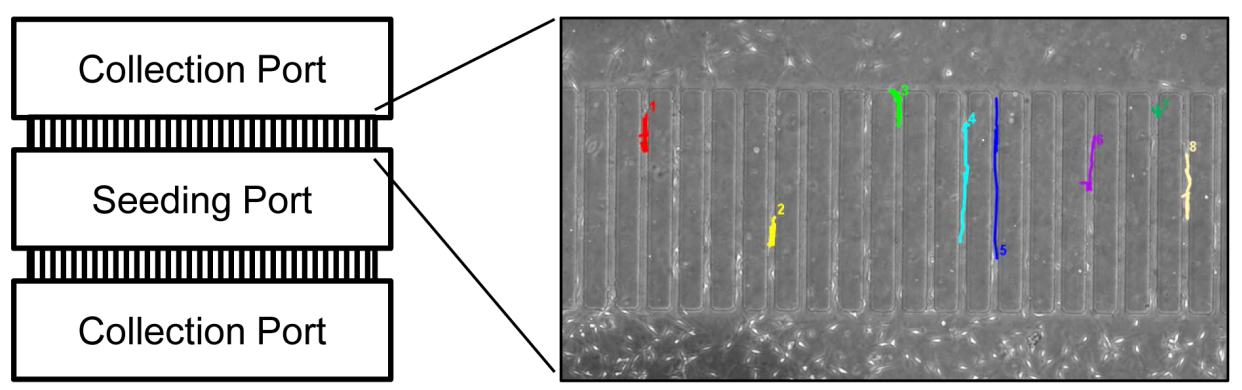

B

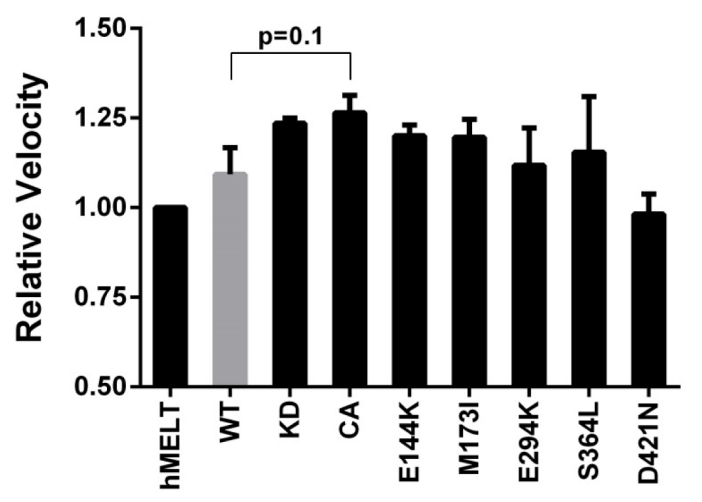

D

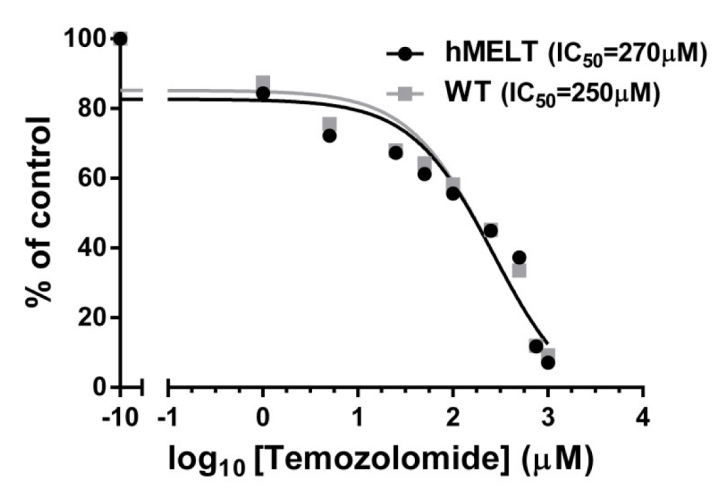

C

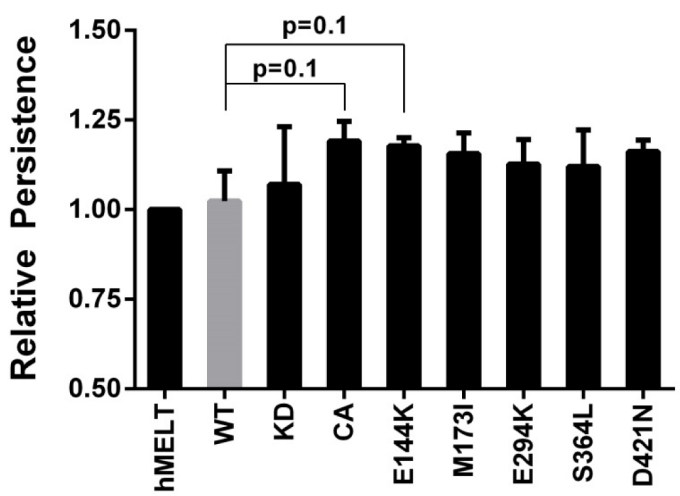

$\mathbf{E}$

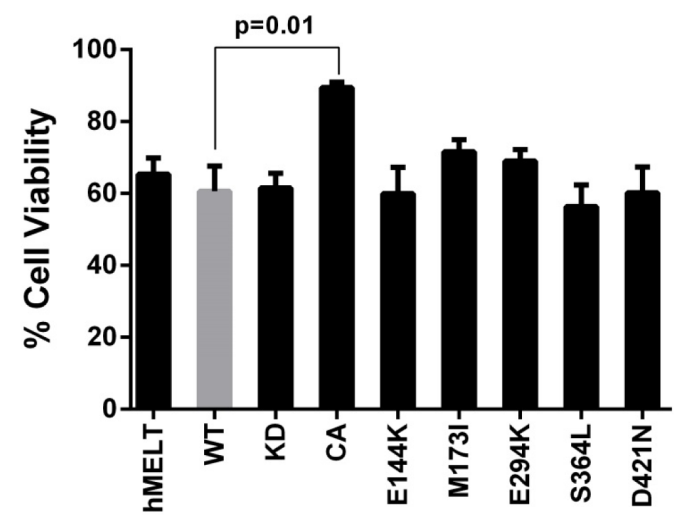

Figure 3: Melanoma-associated PAK5 mutants do not affect in vitro melanocyte migration or resistance to temozolomide. A. hMELT stable cell lines were placed in the seeding port of the depicted microfluidics device. These cells were serum-starved while full serum medium was added to the flanking collection ports to stimulate migration. Using time-lapse microscopy, images were taken every five minutes for a total of twelve hours. Shown is a representative image of cell tracking through the microfluidics device channels using ImageJ. B. The average speed $(\mu \mathrm{m} / \mathrm{min})$ at which hMELT stable cell lines traversed the microfluidics device is shown relative to the parental line. Each bar represents $>130$ analyzed cells across at least three biological replicates with standard error of the mean indicated. $p$-values were calculated using multiple t-tests and significance determined by FDR $(\mathrm{Q}=5 \%)$. $\mathrm{C}$. The ability of single cells to persistently migrate in one direction is shown for each PAK5 mutant relative to the parental line. Each bar represents $>130$ analyzed cells across at least three biological replicates with standard error of the mean indicated. $p$-values were calculated using multiple t-tests and significance determined by FDR $(\mathrm{Q}=5 \%)$. D. hMELT parental and wildtype (WT) PAK5 cells were seeded in a 96-well plate and treated with various concentrations of temozolomide ranging from $0 \mu \mathrm{M}$ to $1 \mathrm{mM}$. Treatment media was changed every two days for a total of seven days after which cell viability was measured using resazurin metabolism. $\mathrm{The}^{\mathrm{IC}_{50}}$ was determined using the ' $\log$ (inhibitor) vs. response (three parameters)' analysis in GraphPad Prism software. E. hMELT-PAK5 stable cell lines were seeded in a 96-well plate and treated with either $250 \mu \mathrm{M}$ temozolomide or DMSO. The treatment media was changed every two days for a total of seven days. Cell viability was measured using resazurin metabolism and normalized to the DMSO control. 'hMELT' indicates the parental cell line. Each bar represents five biological replicates performed in triplicate with the mean and standard error of the mean indicated. $p$-values were calculated using multiple t-tests and significance determined by $\operatorname{FDR}(\mathrm{Q}=5 \%)$. 
$\beta$-CATENIN, CREB or MITF (data not shown). However, using an antibody raised against phosphorylated substrates of the AGC kinases, PKA, PKC, and PKG, we found that hMELT cells expressing PAK5 S364L or D421N exhibited heightened activation of these pathways in comparison to wildtype control cells. Furthermore, this increase was eliminated in hMELT cells expressing PAK5 S364L-KD or D421N-KD. These results indicate that mitogenic PAK5 mutants hyperactivate AGC protein kinases to stimulate melanocyte proliferation (Figure 6A).

Based on these observations, we examined the effect of the PKA inhibitor, H89, on the proliferation of our hMELT stable cell lines. H89 is known to have offtarget effects against other AGC kinases, but exhibits $>10$-fold selectivity for PKA over PKG and $>500$-fold over PKC [69]. Initial studies indicated that $10 \mu \mathrm{M}$ H89 reduced AGC signaling by more than $50 \%$ in hMELT cells expressing wildtype PAK5 cells (Supplementary Figure $3 \mathrm{~A}, 3 \mathrm{~B}$ ). In vitro kinase assays confirmed that this reduction in activity was not attributed to inhibition of PAK5 (Supplementary Figure 3C). Therefore, we performed proliferation assays, treating PAK5 wildtype, M173I, S364L, and D421N expressing cells with $10 \mu \mathrm{M}$ H89 30 minutes prior to, and throughout, the eight-hour EdU labeling period. The proliferation rates of hMELT cells expressing PAK5 S364L or D421N were reduced following H89 treatment (Figure 6B, Supplementary Figure 3D, Supplementary Figure 3E). However, the H89-treated PAK5 S364L and D421N expressing cells still proliferated faster than wildtype control cells $(p=$ $0.01)$. These results reveal the ability of PAK5 to regulate PKA signaling and demonstrate that the mitogenic activity of PAK5 S364L and D421N functions in part through increased PKA signaling.

\section{DISCUSSION}

These studies establish PAK5 as the most frequently altered PAK-family member in human melanoma (Figure 1A). Based upon mutational rates published by TCGA, the 2,160 base pair PAK5 coding sequence should be randomly mutated in $3.6 \%$ of melanoma cases [1]. However, we find that $15 \%$ of melanomas contain a PAK5 missense mutation (Figure 1A), suggesting that alterations in this gene are advantageous to tumor development and/or progression. To elucidate these functions, we characterized the most frequently observed PAK5 mutants in human melanoma (E144K, M173I, E294K, S364L, and D421N). While PAK5 alterations are rare in tumor types other than melanoma (Supplementary Figure 1A), the mutants characterized by our study appear in additional tumor sequencing datasets. Specifically, PAK5 E144K has been observed in colorectal adenocarcinomas, PAK5 S364L in lung adenocarcinomas, colon adenocarcinomas, and uterine endometrioid tumors, and PAK5 D421N in multiple lung adenocarcinomas [51, 70-73]. Beyond single nucleotide variants, $5.1 \%$ of melanomas exhibit elevated PAK5 mRNA levels similar to the increased expression of other $P A K$ family members in human cancer (Figure 1A) [33]. This observation implies that elevated PAK5 activity is advantageous to the tumor and prompted our investigation of potential gain-of-function phenotypes elicited by common, melanoma-associated PAK5 missense mutations.

Our findings show that although the kinase activity of common, melanoma-associated PAK5 mutants is unaltered in vitro, a subset of these variants (PAK5 S364L and $\mathrm{D} 421 \mathrm{~N}$ ) are able to promote melanocyte proliferation (Figures 2C, 4A, 5B, 6B). These data support a model in which PAK5 S364L and D421N engage mitogenic signaling pathways more effectively than the wildtype protein (Figure 6C). Such engagement could come in the form of increased affinity for wildtype substrates and/or the acquisition of novel binding partners. In accordance with this model, it remains possible that melanomaassociated PAK5 mutants alter single-cell migration and/ or temozolomide resistance in the context of specific cancer proteomes. We see that a subset of PAK5 mutants are capable of stimulating ERK activation even in the absence of PAK5 kinase activity. However, the impact of this inappropriate ERK activation appears dependent upon how sensitive the cells are to MAPK-stimulated proliferation.

The PAK5 S364L and D421N mutants lie within a disordered and largely uncharacterized protein domain flanked by two proline-rich PxxP repeats (Figure 2A, orange boxes) $[54,74]$. This domain extends from amino acids 351 to 445 , is serine-rich (28\%), and harbors $23 \%$ of all PAK 5 missense mutations reported in the provisional TCGA melanoma dataset [51]. Our model predicts that PAK5 S364L and D421N alter the PAK5 interactome to promote melanocyte proliferation and is consistent with the conclusion that this serine-rich domain may be important for PAK5 protein interactions. This hypothesis is supported by a recent study showing that a region of PAK4, homologous to PAK5 amino acids 426-452, interacts with the Rho-family guanine nucleotide exchange factor, GEF-H1 [75]. Other work predicts that the PAK4 Q358 and R359 residues, which are conserved amongst group II PAKs and equivalent to PAK5 residues Q486 and R487, mediate substrate-selective differences between the group I and II PAKs [54]. Changing these amino acids to the corresponding PAK2 residues results in a PAK4 protein that preferentially binds group I, rather than group II peptide substrates [54]. These data suggest that the region surrounding these amino acids is critical for group II PAK substrate interactions. Furthermore, the PAK5 serinerich domain shares $75 \%$ homology with other group II PAKs and mutations localized to this region are observed across multiple tumor datasets deposited in cBioPortal [51]. As PAKs interact with substrates involved in diverse tumorigenic processes, mutations that impact these 
A

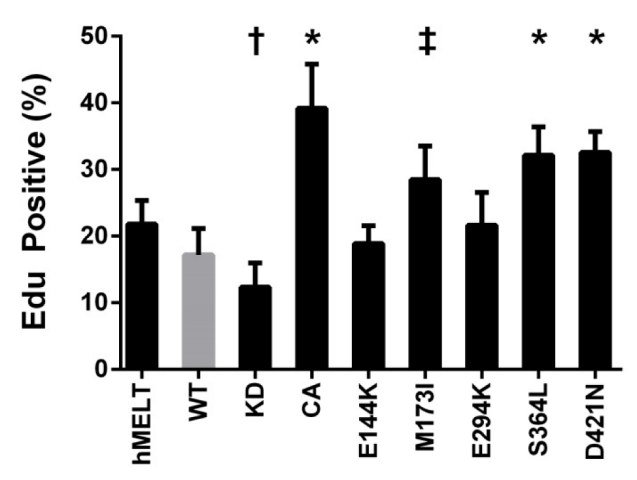

C

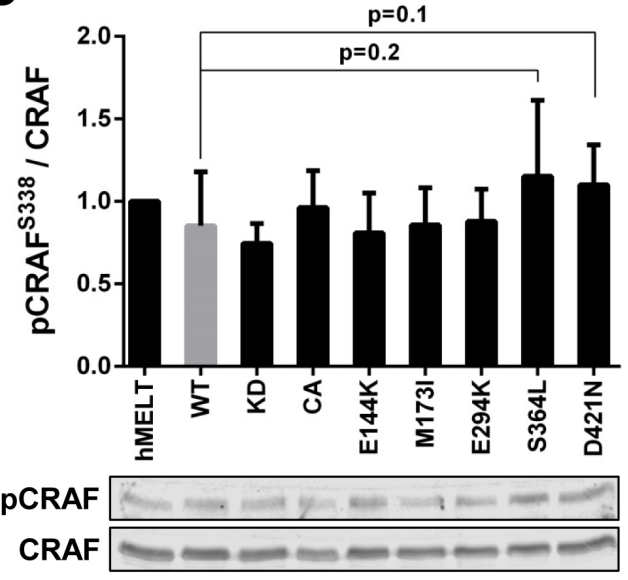

B

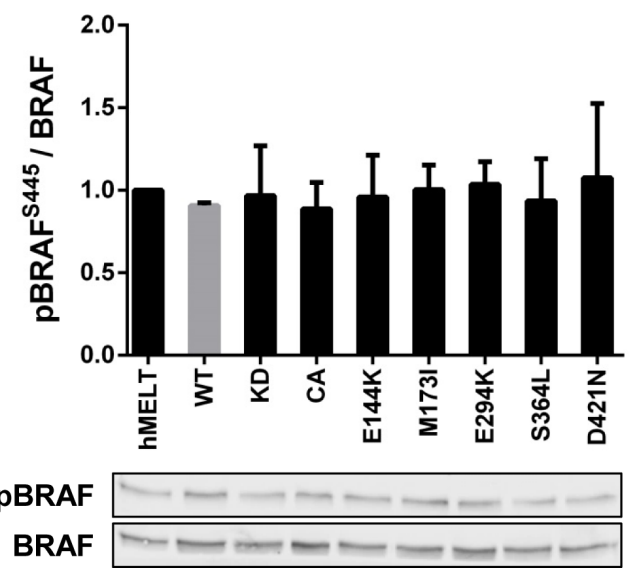

D

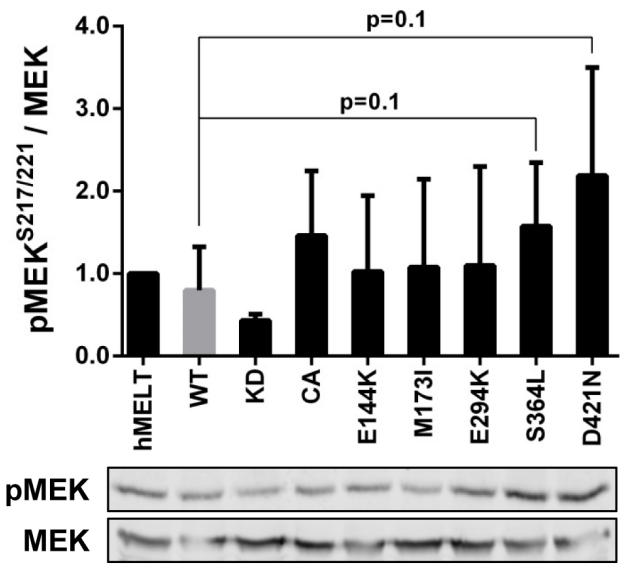

E

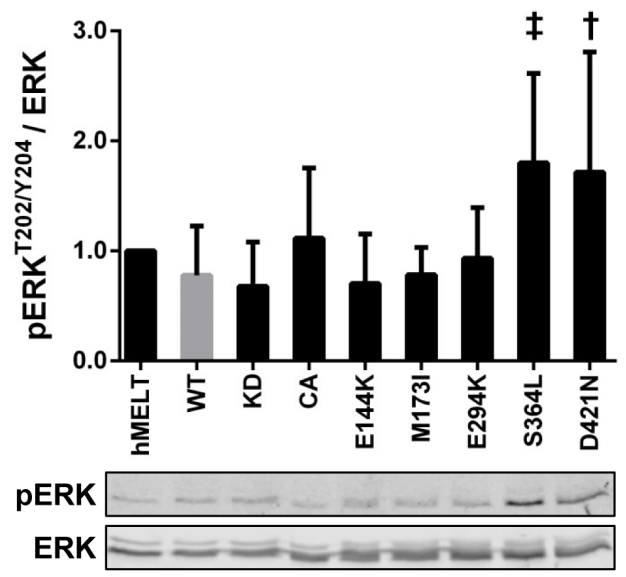

Figure 4: PAK5 S364L and D421N promote melanocyte proliferation and ERK activation. A. hMELT stable cell lines were placed in $2 \%$ serum for 18 hours and then labeled with EdU for eight hours. After labeling, cells were fixed for flow cytometric analysis. Shown is the average percentage of EdU positive cells across at least three biological replicates with error bars representing the standard deviation. $\dagger=p<0.05, t=p<0.01, *=p<0.001$ compared to PAK5 WT (gray bar), where $p$-values were calculated using multiple $\mathrm{t}$-tests and significance determined by FDR $(\mathrm{Q}=5 \%)$. 'hMELT' indicates the parental cell line. B.-E. Lysates from hMELT stable cell lines, incubated in $2 \%$ serum as described in 'A', were analyzed by SDS-PAGE followed by immunoblotting. Bar graphs show phospho-protein levels normalized to total protein and relative to parental hMELT cells. At least four biological replicates were run with the mean and standard deviation indicated. A representative immunoblot is shown below each graph. $\dagger=p<0.05$, $\$=p<0.01$, compared to PAK5 WT (gray bar), where $p$-values were calculated using multiple t-tests and significance determined by FDR $(\mathrm{Q}=5 \%)$. 
protein:protein interactions may drive tumor progression. Notably, post-translational modifications in the serinerich domain have yet to be documented and although the central region of PAK5 (aa109-420) is reported to elevate kinase activity through oligomerization, the catalytic activity of PAK5 S364L and D421N is unchanged (Figure 2C) $[76,77]$. Taken together, these data support a model in which the unstructured, serine-rich domain proximal to the PAK5 kinase domain is important for mediating PAK5:substrate interactions and that alterations within this region can give rise to tumorigenic consequences.

Our findings show that PAK5 S364L and D421N alter intracellular signaling through both kinaseindependent and -dependent functions. As an example of these kinase-independent functions, we find that the expression of either PAK5 S364L-KD or D421N-KD enhances ERK phosphorylation (Figure 5A). A similar kinase-independent phenotype, attributed to the improved scaffolding of proteins within the MAPK pathway, is reported in colon cancer cell lines overexpressing a kinase dead version of PAK1 [32]. While prior publications show that PAKs, including PAK5, can directly phosphorylate members of the MAPK signaling cascade [59-64], our data indicate that the kinase-independent functions of PAK5 S364L and D421N are sufficient to stimulate ERK activation in melanocytes. Nevertheless, the mitogenic effect of these mutants in hMELTs is maximized when catalytic activity is intact, and we identified PKA as one kinase-dependent pathway required to drive aberrant melanocyte proliferation (Figure 6A, 6B). While PKA is known to directly phosphorylate PAK 1 and 4 in other cell types [78-81], our studies are the first to show that PAK5
A

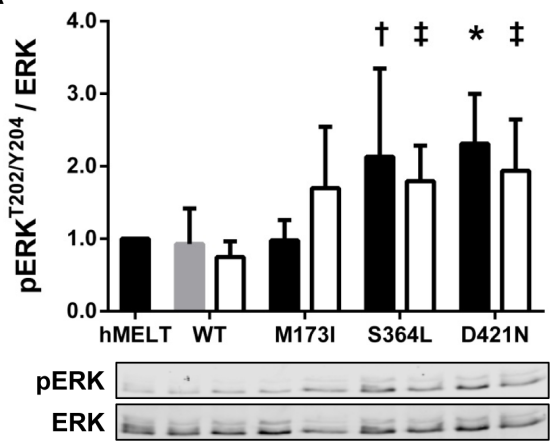

C

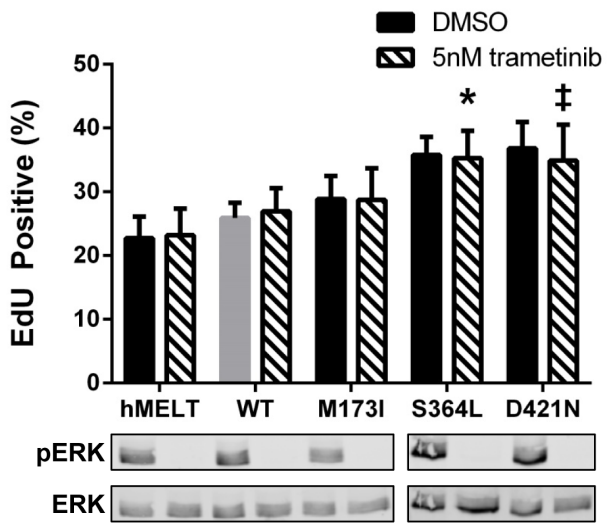

B

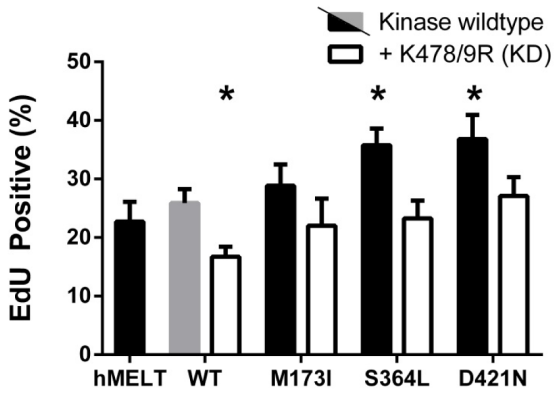

Figure 5: Kinase-independent functions of PAK5 S364L and D421N activate ERK but do not promote proliferation. A. Lysates from hMELT stable cell lines, incubated in 2\% serum for 18 hours, were analyzed by SDS-PAGE followed by immunoblotting. Bar graphs show phospho-protein levels normalized to total protein and relative to parental hMELT cells. At least four biological replicates were run with the mean and standard deviation indicated. A representative immunoblot is shown below. $\dagger=p<0.05, \dagger=p<0.01, *=$ $p<0.001$ compared to PAK5 WT (gray bar), where $p$-values were calculated using multiple t-tests and significance determined by FDR $(\mathrm{Q}=$ $5 \%$ ). B. The proliferation of hMELT stable cell lines was analyzed as in Figure 4A. Shown is the average percentage of cells staining EdU positive across at least three biological replicates with error bars representing the standard deviation. $*=p<0.001$ compared to PAK5 WT (gray bar), where $p$-values were calculated using multiple t-tests and significance determined by FDR (Q $=5 \%)$. C. hMELT stable cell lines were treated with $5 \mathrm{~nm}$ trametinib 30 minutes prior to the addition of EdU. Shown is the average percentage of cells staining EdU positive across at least three biological replicates with error bars representing standard deviation. $\dagger=p<0.05, \dagger=p<0.01$, compared to trametinibtreated PAK5 WT (dashed gray bar), where $p$-values were calculated using multiple t-tests and significance determined by FDR $(\mathrm{Q}=5 \%)$. ' $h M E L T$ ' indicates the parental cell line. 
functions upstream of PKA signaling and may reflect a regulatory pathway specific to melanocytes.

Only one other report has examined the role of PAK5 missense mutations in cancer prior to our study. This publication focused on several lung-cancer-associated variants located near the serine-rich, unstructured domain (i.e. S312C, V463L, T538N, and V593I) [82]. Like PAK5 S364L and D421N, the authors showed that these mutants are capable of activating MAPK signaling; however, the ability of these proteins to drive aberrant proliferation in the presence or absence of kinase-activity was not explored. Nevertheless, these data bolster our hypothesis that the serine-rich domain of PAK5 engages mitogenic signaling pathways, and that mutations within this domain could enhance these interactions to drive cell cycle entry.

Efforts to develop effective PAK inhibitors have been hindered by poor specificity and high toxicity [43]. Our data suggest that targeting specific PAK interactomes may improve therapeutic results. Along this line, two prior studies identify peptides that block the interaction of PAK1 with SH3-domain proteins [83]. Use of these selective peptides prevents cellular transformation and
A

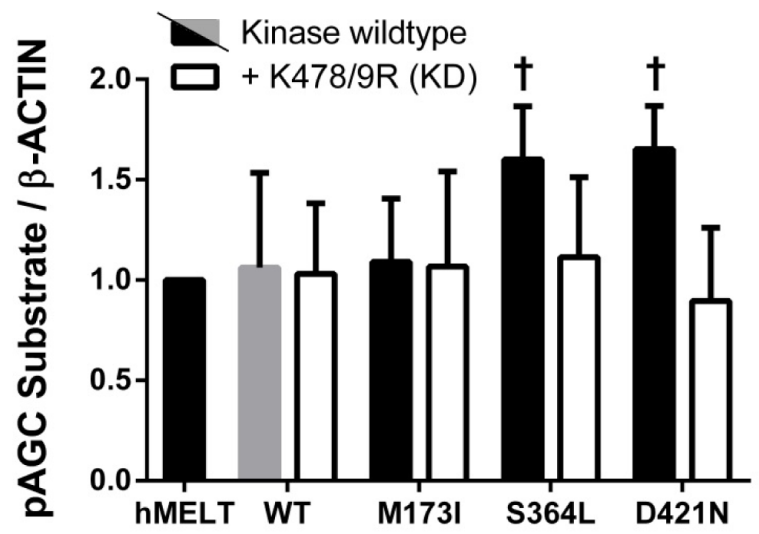

B

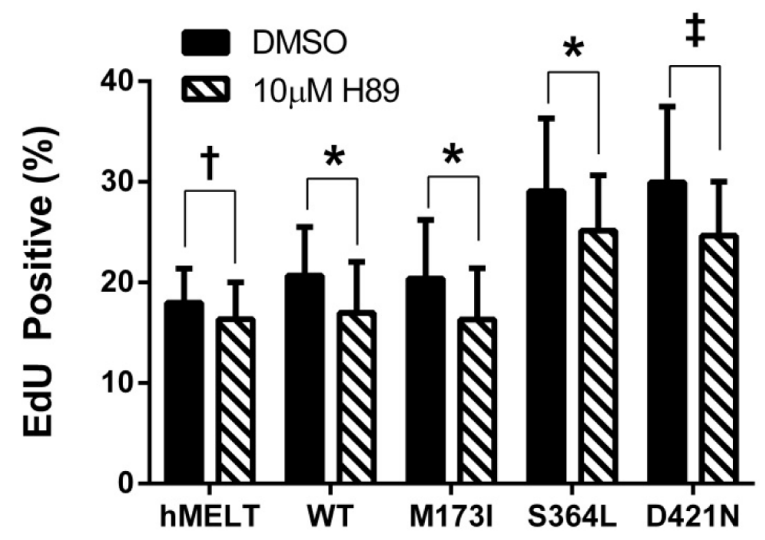

C

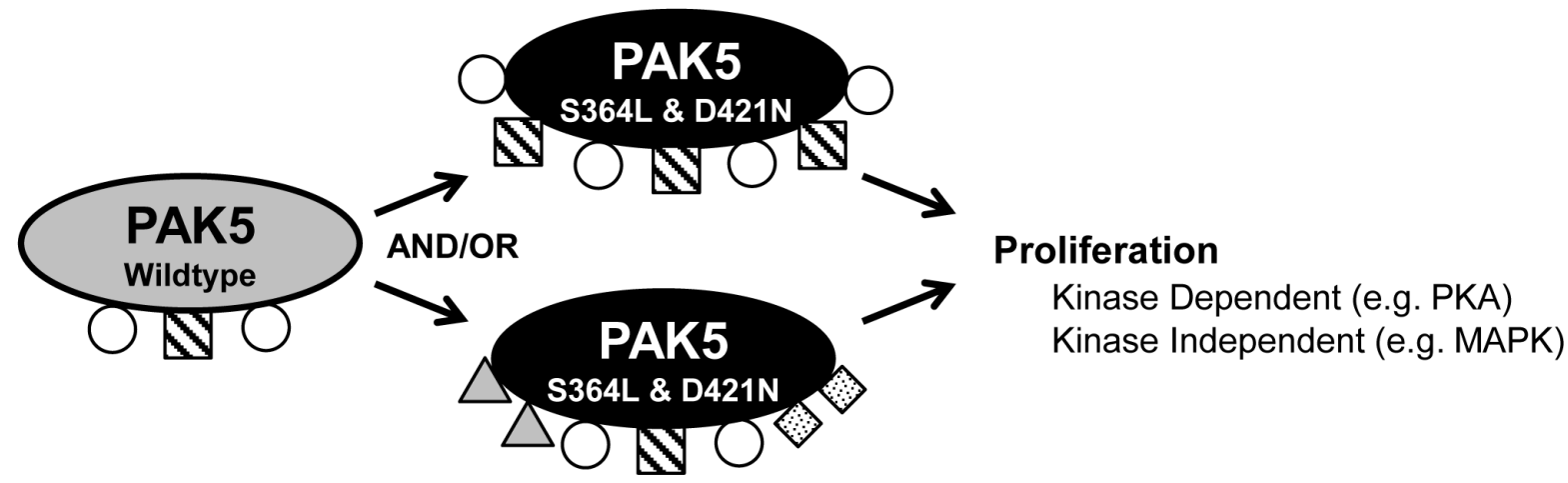

Figure 6: PAK5 S364L and D421N promote proliferation through PKA activation. A. Lysates from hMELT stable cell lines, incubated in 2\% serum for 18 hours, were analyzed by SDS-PAGE followed by immunoblotting with an antibody that recognizes the phosphorylated substrate motif of AGC kinases. 'hMELT' indicates the parental cell line. Each bar indicates the average, $\beta$-ACTINnormalized, pAGC substrate signal relative to parental hMELT cells across at least three biological replicates. Error bars represent the standard deviation. $\uparrow=p<0.05$ compared to PAK5 WT (gray bar), where $p$-values were calculated using multiple t-tests and significance determined by FDR $(\mathrm{Q}=5 \%)$. B. hMELT stable cell lines were treated with $10 \mu \mathrm{M}$ H89 or vehicle (DMSO) 30 minutes prior to the addition of EdU. Shown is the average percentage of EdU positive cells across at least three biological replicates with error bars representing the standard deviation. 'hMELT' indicates the parental cell line. $\dagger=p<0.05, \dagger=p<0.01, *=p<0.001$ compared to PAK5 WT (gray bar), where $p$-values were calculated using a paired t-test. C. Model showing the proposed mechanism by which PAK5 S364L and D421N promote melanocyte proliferation. 
migration in cell culture models. Taken together, these data provide the impetus to comprehensively characterize the PAK5 interactome and identify regions of the protein essential for pro-tumorigenic functions.

\section{MATERIALS AND METHODS}

\section{Cell culture}

Primary human melanocytes immortalized with hTERT and CDK4 ${ }^{\mathrm{R} 24 \mathrm{C}}$ (hMELTs) [65], were maintained in Ham's F12 supplemented with 7\% FBS, 1\% penicillinstreptomycin, $2 \mathrm{mmol} / \mathrm{L}$ L-glutamine, $50 \mathrm{ng} / \mathrm{ml}$ TPA, $100 \mu \mathrm{M}$ IBMX, $1 \mu \mathrm{M} \mathrm{Na} \mathrm{VO}_{4}$, and $50 \mu \mathrm{M}$ dbcAMP. HEK293T (ATCC CRL-3216) cells were cultured in DMEM supplemented with 5\% FBS, 1\% penicillinstreptomycin, and $2 \mathrm{mmol} / \mathrm{L} \mathrm{L}$-glutamine. To generate stable cell lines, hMELTs were transduced with lentivirus in the presence of $10 \mu \mathrm{g} / \mathrm{ml}$ polybrene (Sigma \#H9268). Stably transduced lines were selected and maintained in $1 \mu \mathrm{g} / \mathrm{mL}$ puromycin beginning two days after viral transduction.

Cell line identity was validated by short tandem repeat analysis (Michigan State Genomics Core) and cultures were regularly tested for mycoplasma contamination using Mycoplasma Plus PCR Primers (Agilent).

\section{Plasmid vectors and lentiviral production}

pDEST-PAK5 was kindly provided by Dr. J. Brognard (CRUK Manchester). Wildtype PAK5 was cloned from the pDEST vector into the BamHI and EcoRI sites of pLenti-puro using Gibson Assembly Master Mix (NEB, \#E2611). The pLenti-puro vector is a derivative of pTRIPZ (Open Biosystems) in which turboRFP and rtTA3 were removed and a multiple cloning sequence inserted between the Bam HI and Not I restriction sites. pLenti-puro PAK5 mutants were generated using PCR mutagenesis and Gibson Assembly Master Mix (NEB, \#E2611). PAK5 lentiviruses were made in HEK293T cells using standard procedures

\section{Immunoblotting}

hMELT-PAK5 stable lines were grown to $70 \%$ confluence and then placed for 18 hours in media containing $2 \%$ serum and no additional growth factors. Cells were lysed in RIPA (150mM NaCl, 1\% IGEPALCA-630, 0.5\% deoxycholate, $0.1 \%$ SDS, $50 \mathrm{mM}$ Tris $\mathrm{pH}$ 8.0) containing protease (Sigma, P8340) and phosphatase (Fisher, 78420) inhibitors, separated by SDS-PAGE and transferred to a PVDF membrane. Resulting membranes were blocked in 5\% milk and incubated with primary antibody overnight at $4^{\circ} \mathrm{C}$. All primary antibodies are listed in Supplemental Materials (Supplementary Table 1). Washed membranes were incubated for 45 minutes at room temperature in secondary antibody solution (LICOR IRDye 680,$800 ; 1: 15000$ in 5\% milk), imaged on an Odyssey ${ }^{\circledR}$ CLx, and quantified using Image Studio Software. $p$-values were calculated using multiple t-tests and significance determined by FDR $(Q=5 \%)$.

\section{In vitro kinase assays}

PAK5 kinase activity was measured using ADPGlo following the Promega protocol. Briefly, FLAGPAK5 was immunoprecipitated from hMELT stable cell lines using anti-FLAG conjugated magnetic beads (Sigma \#M8823). After washing the beads three times with $150 \mathrm{mM}$ RIPA for 5 minutes on a rotator, purified FLAG-PAK 5 was incubated with $0.2 \mathrm{mg} / \mathrm{ml} \mathrm{AKT} \mathrm{(PKB)}$ substrate (CKRPRAASFAE; SignalChem \#A05-58), 50 $\mu \mathrm{M}$ UltraPure ATP, and Kinase Reaction Buffer A (40 $\mathrm{mM}$ Tris $\mathrm{pH} 7.5,20 \mathrm{mM} \mathrm{MgCl}_{2}, 0.1 \mathrm{mg} / \mathrm{ml} \mathrm{BSA}$ ) for 15 minutes at room temperature. The kinase reaction was quenched with ADP Glo Reagent for 40 minutes and then Kinase Detection Reagent was added for 30 minutes at room temperature. Luciferase activity was measured using a Veritas ${ }^{\mathrm{TM}}$ Microplate Luminometer with 1 second of integration. Raw Luciferase measurements were normalized to the amount of FLAGPAK5 immunoprecipitated, which was quantified from immunoblots using Image Studio Software. $p$-values were calculated using multiple t-tests and significance determined by $\operatorname{FDR}(\mathrm{Q}=5 \%)$.

\section{Migration assays}

hMELT stable cell lines were analyzed for migratory defects using a microfluidics device $(20 \mu \mathrm{m}$ width x 20 $\mu \mathrm{m}$ height x $700 \mu \mathrm{m}$ length) (See Supplemental Materials for device manufacturing details). Microfluidic devices were treated with $10 \mu \mathrm{g} / \mathrm{ml}$ fibronectin for one hour. 600,000 cells were then introduced into the center seeding port of the microfluidics device containing normal growth media. The next day, cells were placed in media containing $0.1 \%$ serum and melanocyte growth factors for 18 hours. Full serum media was added to the outside collection ports to create a gradient. Images were taken every 5 minutes for 12 hours on a BioTek Lionheart FX Automated Microscope. The average velocity $(\mu \mathrm{m} / \mathrm{min})$ and persistence of single cells traversing the channels were calculated using the MTrackJ plugin for ImageJ [83]. Persistence was calculated for each cell by dividing the cellular displacement by the total distance traveled. 
$p$-values were calculated using multiple t-tests and significance determined by FDR $(Q=5 \%)$.

\section{Cell viability assays}

30,000 hMELT stable cell lines were seeded in black-walled 96-well plates (Thermo Scientific \#165305) coated with poly-L-lysine (Sigma \#P1274). The next day, cells were treated with either DMSO or temozolomide (Sigma \#T2577). Treatment media was changed every two days for a total of 7 days. On the $7^{\text {th }}$ day, cells were incubated with $0.0036 \%$ resazurin (Sigma \#R7017) for one hour at $37^{\circ} \mathrm{C}$ and fluorescence measured in a BioTek Synergy ${ }^{\text {TM }}$ HT microplate reader using 540/59 excitation/ emission filters. $p$-values were calculated using multiple t-tests and significance determined by FDR $(Q=5 \%)$.

\section{EdU incorporation and flow cytometry}

hMELT stable cell lines were seeded at equal density, placed for 18 hours in medium containing $2 \%$ serum and no additional growth factors, and then incubated with $10 \mu \mathrm{M}$ EdU for 8 hours. Cells were harvested and processed as described in the Click-iT EdU Flow Cytometry Assay Kit (Invitrogen \#C10634). Briefly, cells were fixed in ice cold 4\% paraformaldehyde, permeabilized in $1 \mathrm{x}$ Invitrogen saponin buffer, and covalently labeled with 642 fluorescent azide (Active Motif \#15288). Cells were run either on a FlowSight flow cytometer (Amnis) and analyzed using IDEAS software or on a BD Biosciences LSRII flow cytometer and analyzed using FlowJo Software. $p$-values were calculated using multiple t-tests and significance determined by FDR (Q $=5 \%$ ).

When investigating the PKA signaling pathways, the hMELT stable cell lines were seeded and processed as described above except for one change. Cells were treated with either DMSO or H89 (Selleckchem \#S1582) 30 minutes prior to and throughout the EdU labeling period. $p$-values were calculated using a paired t-test.

\section{Abbreviations}

PAK: p21-Activated Kinase; hMELT: Human Immortalized Primary Melanocytes; AID: Auto-inhibitory Domain; TCGA: The Cancer Genome Atlas.

\section{Author contributions}

KML and CEB conceived and designed the study. KML, DCV, AAG, and XG performed the experiments. KML, DCV, AAG, JLH, JWS, CEB analyzed and interpreted the data. KML and CEB wrote the manuscript. All authors read and approved the final version of the manuscript.

\section{ACKNOWLEDGMENTS}

The authors thank members of the Analytical Cytometry Shared Resource (ACSR) at The Ohio State University Comprehensive Cancer Center, Columbus, $\mathrm{OH}$, for technical support. In addition, we acknowledge Drs. H. Windlund (Harvard), L. Garraway (Dana-Farber), and J. Brognard (CRUK Manchester) for critical reagents and Dr. R. Fishel (OSU), A. Holderbaum (OSU), B. Hennessey (OSU), B. Murphy (OSU), and C. Haines (OSU) for critical reading of the manuscript. Research reported in this publication was supported by The Ohio State University Comprehensive Cancer Center and the National Institutes of Health under grant number P30CA016058. The content is solely the responsibility of the authors and does not necessarily represent the official views of the National Institutes of Health. The project described was supported by Award Number UL1TR001070 from the National Center for Advancing Translational Sciences. The content is solely the responsibility of the authors and does not necessarily represent the official views of the National Center for Advancing Translational Sciences or the National Institutes of Health.

\section{CONFLICTS OF INTEREST}

The authors declare no affiliations and/or financial interests related to the contents of this manuscript.

\section{FUNDING}

This work was supported by grants from the Melanoma Research Alliance (309669; C.E.B), CCTS (K.M.L), and Pelotonia (K.M.L.).

\section{REFERENCES}

1. Cancer Genome Atlas Network. Genomic Classification of Cutaneous Melanoma. Cell. 2015; 161:1681-96.

https://doi.org/10.1016/j.cell.2015.05.044.

2. Hennessey RC, Holderbaum AM, Bonilla A, Delaney C, Gillahan JE, Tober KL, Oberyszyn TM, Zippin JH, Burd CE. Ultraviolet radiation accelerates NRas-mutant melanomagenesis: A cooperative effect blocked by sunscreen. Pigment Cell Melanoma Res. 2017; 30:477-87. https://doi.org/10.1111/pcmr.12601.

3. Dankort D, Curley DP, Cartlidge RA, Nelson B, Karnezis AN, Damsky WE Jr, You MJ, DePinho RA, McMahon M, Bosenberg M. Braf(V600E) cooperates with Pten loss to induce metastatic melanoma. Nat Genet. 2009; 41:544-52. https://doi.org/10.1038/ng.356.

4. Viros A, Sanchez-Laorden B, Pedersen M, Furney SJ, Rae J, Hogan K, Ejiama S, Girotti MR, Cook M, Dhomen 
N, Marais R. Ultraviolet radiation accelerates BRAFdriven melanomagenesis by targeting TP53. Nature. 2014; 511:478-82. https://doi.org/10.1038/nature13298.

5. Ferguson B, Konrad Muller H, Handoko HY, Khosrotehrani K, Beermann F, Hacker E, Soyer HP, Bosenberg M, Walker GJ. Differential roles of the $\mathrm{pRb}$ and Arf/p53 pathways in murine naevus and melanoma genesis. Pigment Cell Melanoma Res. 2010; 23:771-80.

https://doi.org/10.1111/j.1755-148X.2010.00752.x.

6. Mukhopadhyay P, Ferguson B, Muller HK, Handoko HY, Walker GJ. Murine melanomas accelerated by a single UVR exposure carry photoproduct footprints but lack UV signature $\mathrm{C}>\mathrm{T}$ mutations in critical genes. Oncogene. 2016; 35:3342-50. https://doi.org/10.1038/onc.2015.386.

7. Ackermann J, Frutschi M, Kaloulis K, McKee T, Trumpp A, Beermann F. Metastasizing melanoma formation caused by expression of activated N-RasQ61K on an INK4adeficient background. Cancer Res. 2005; 65:4005-11. https://doi.org/10.1158/0008-5472.CAN-04-2970.

8. Maertens O, Johnson B, Hollstein P, Frederick DT, Cooper ZA, Messiaen L, Bronson RT, McMahon M, Granter S, Flaherty K, Wargo JA, Marais R, Cichowski K. Elucidating distinct roles for NF1 in melanomagenesis. Cancer Discov. 2013; 3:338-49.

https://doi.org/10.1158/2159-8290.CD-12-0313.

9. Shain AH, Yeh I, Kovalyshyn I, Sriharan A, Talevich E, Gagnon A, Dummer R, North J, Pincus L, Ruben B, Rickaby W, D'Arrigo C, Robson A, Bastian BC. the genetic evolution of melanoma from precursor lesions. N Engl J Med. 2015; 373:1926-36.

https://doi.org/10.1056/NEJMoa1502583.

10. Tsao H, Bevona C, Goggins W, Quinn T. The transformation rate of moles (melanocytic nevi) into cutaneous melanoma: a population-based estimate. Arch Dermatol. 2003; 139:282-88.

https://doi.org/10.1001/archderm.139.3.282.

11. Boespflug A, Caramel J, Dalle S, Thomas L. Treatment of NRAS-mutated advanced or metastatic melanoma: rationale, current trials and evidence to date. Ther Adv Med Oncol. 2017; 9:481-92.

https://doi.org/10.1177/1758834017708160.

12. Chapman PB, Hauschild A, Robert C, Haanen JB, Ascierto P, Larkin J, Dummer R, Garbe C, Testori A, Maio M, Hogg D, Lorigan P, Lebbe C, et al, and BRIM-3 Study Group. Improved survival with vemurafenib in melanoma with BRAF V600E mutation. N Engl J Med. 2011; 364:250716. https://doi.org/10.1056/NEJMoa1103782.

13. Hauschild A, Grob JJ, Demidov LV, Jouary T, Gutzmer R, Millward M, Rutkowski P, Blank CU, Miller WH Jr, Kaempgen E, Martín-Algarra S, Karaszewska B, Mauch C, et al. Dabrafenib in BRAF-mutated metastatic melanoma: a multicentre, open-label, phase 3 randomised controlled trial. Lancet. 2012; 380:358-65.

https://doi.org/10.1016/S0140-6736(12)60868-X.
14. Flaherty KT, Robert C, Hersey P, Nathan P, Garbe C, Milhem M, Demidov LV, Hassel JC, Rutkowski P, Mohr P, Dummer R, Trefzer U, Larkin JM, et al, and METRIC Study Group. Improved survival with MEK inhibition in BRAF-mutated melanoma. N Engl J Med. 2012; 367:10714. https://doi.org/10.1056/NEJMoa1203421.

15. Flaherty KT, Infante JR, Daud A, Gonzalez R, Kefford RF, Sosman J, Hamid O, Schuchter L, Cebon J, Ibrahim N, Kudchadkar R, Burris HA 3rd, Falchook G, et al. Combined BRAF and MEK inhibition in melanoma with BRAF V600 mutations. N Engl J Med. 2012; 367:1694-703.

https://doi.org/10.1056/NEJMoa1210093.

16. Ribas A, Gonzalez R, Pavlick A, Hamid O, Gajewski TF, Daud A, Flaherty L, Logan T, Chmielowski B, Lewis $\mathrm{K}$, Kee D, Boasberg P, Yin M, et al. Combination of vemurafenib and cobimetinib in patients with advanced BRAF(V600)-mutated melanoma: a phase 1b study. Lancet Oncol. 2014; 15:954-65.

https://doi.org/10.1016/S1470-2045(14)70301-8.

17. Chalmers ZR, Connelly CF, Fabrizio D, Gay L, Ali SM, Ennis R, Schrock A, Campbell B, Shlien A, Chmielecki J, Huang F, He Y, Sun J, et al. Analysis of 100,000 human cancer genomes reveals the landscape of tumor mutational burden. Genome Med. 2017; 9:34.

https://doi.org/10.1186/s13073-017-0424-2.

18. Lawrence MS, Stojanov P, Polak P, Kryukov GV, Cibulskis K, Sivachenko A, Carter SL, Stewart C, Mermel CH, Roberts SA, Kiezun A, Hammerman PS, McKenna A, et al. Mutational heterogeneity in cancer and the search for new cancer-associated genes. Nature. 2013; 499:214-18.

https://doi.org/10.1038/nature12213.

19. Alexandrov LB, Nik-Zainal S, Wedge DC, Aparicio SA, Behjati S, Biankin AV, Bignell GR, Bolli N, Borg A, Børresen-Dale AL, Boyault S, Burkhardt B, Butler AP, et al, and Australian Pancreatic Cancer Genome Initiative, and ICGC Breast Cancer Consortium, and ICGC MMML-Seq Consortium, and ICGC PedBrain. Signatures of mutational processes in human cancer. Nature. 2013; 500:415-21. https://doi.org/10.1038/nature12477.

20. Jaffer ZM, Chernoff J. p21-activated kinases: three more join the Pak. Int J Biochem Cell Biol. 2002; 34:713-17. https://doi.org/10.1016/S1357-2725(01)00158-3.

21. Lei M, Lu W, Meng W, Parrini MC, Eck MJ, Mayer BJ, Harrison SC. Structure of PAK1 in an autoinhibited conformation reveals a multistage activation switch. Cell. 2000; 102:387-97. https://doi.org/10.1016/S0092-8674(00)00043-X.

22. Buchwald G, Hostinova E, Rudolph MG, Kraemer A, Sickmann A, Meyer HE, Scheffzek K, Wittinghofer A. Conformational switch and role of phosphorylation in PAK activation. Mol Cell Biol. 2001; 21:5179-89.

https://doi.org/10.1128/MCB.21.15.5179-5189.2001.

23. Pirruccello M, Sondermann H, Pelton JG, Pellicena P, Hoelz A, Chernoff J, Wemmer DE, Kuriyan J. A dimeric 
kinase assembly underlying autophosphorylation in the p21 activated kinases. J Mol Biol. 2006; 361:312-26.

https://doi.org/10.1016/j.jmb.2006.06.017.

24. Baskaran Y, Ng YW, Selamat W, Ling FT, Manser E. Group I and II mammalian PAKs have different modes of activation by Cdc42. EMBO Rep. 2012; 13:653-59.

https://doi.org/10.1038/embor.2012.75.

25. Ha BH, Davis MJ, Chen C, Lou HJ, Gao J, Zhang R, Krauthammer M, Halaban R, Schlessinger J, Turk BE, Boggon TJ. Type II p21-activated kinases (PAKs) are regulated by an autoinhibitory pseudosubstrate. Proc Natl Acad Sci USA. 2012; 109:16107-12.

https://doi.org/10.1073/pnas.1214447109.

26. Daniels RH, Hall PS, Bokoch GM. Membrane targeting of p21-activated kinase 1 (PAK1) induces neurite outgrowth from PC12 cells. EMBO J. 1998; 17:754-64.

https://doi.org/10.1093/emboj/17.3.754.

27. Frost JA, Khokhlatchev A, Stippec S, White MA, Cobb MH. Differential effects of PAK1-activating mutations reveal activity-dependent and -independent effects on cytoskeletal regulation. J Biol Chem. 1998; 273:28191-98. https://doi.org/10.1074/jbc.273.43.28191.

28. Obermeier A, Ahmed S, Manser E, Yen SC, Hall C, Lim L. PAK promotes morphological changes by acting upstream of Rac. EMBO J. 1998; 17:4328-39.

https://doi.org/10.1093/emboj/17.15.4328.

29. Sundberg-Smith LJ, Doherty JT, Mack CP, Taylor JM. Adhesion stimulates direct PAK1/ERK2 association and leads to ERK-dependent PAK1 Thr212 phosphorylation. J Biol Chem. 2005; 280:2055-64. https://doi.org/10.1074/jbc.M406013200.

30. Higuchi M, Onishi K, Kikuchi C, Gotoh Y. Scaffolding function of PAK in the PDK1-Akt pathway. Nat Cell Biol. 2008; 10:1356-64. https://doi.org/10.1038/ncb1795.

31. Ijuin $\mathrm{T}$, Takenawa $\mathrm{T}$. Regulation of insulin signaling by the phosphatidylinositol 3,4,5-triphosphate phosphatase SKIP through the scaffolding function of Pak1. Mol Cell Biol. 2012; 32:3570-84. https://doi.org/10.1128/MCB.00636-12.

32. Wang Z, Fu M, Wang L, Liu J, Li Y, Brakebusch C, Mei Q. p21-activated kinase 1 (PAK1) can promote ERK activation in a kinase-independent manner. J Biol Chem. 2013; 288:20093-99. https://doi.org/10.1074/jbc.M1 12.426023.

33. King H, Nicholas NS, Wells CM. Role of p-21-activated kinases in cancer progression. Int Rev Cell Mol Biol. 2014; 309:347-87.

https://doi.org/10.1016/B978-0-12-800255-1.00007-7.

34. Shrestha Y, Schafer EJ, Boehm JS, Thomas SR, He F, Du J, Wang S, Barretina J, Weir BA, Zhao JJ, Polyak K, Golub TR, Beroukhim R, Hahn WC. PAK1 is a breast cancer oncogene that coordinately activates MAPK and MET signaling. Oncogene. 2012; 31:3397-408.

https://doi.org/10.1038/onc.2011.515.

35. Brown LA, Kalloger SE, Miller MA, Shih IM, McKinney
SE, Santos JL, Swenerton K, Spellman PT, Gray J, Gilks CB, Huntsman DG. Amplification of 11q13 in ovarian carcinoma. Genes Chromosomes Cancer. 2008; 47:481-89. https://doi.org/10.1002/gcc.20549.

36. Davis SJ, Sheppard KE, Pearson RB, Campbell IG, Gorringe KL, Simpson KJ. Functional analysis of genes in regions commonly amplified in high-grade serous and endometrioid ovarian cancer. Clin Cancer Res. 2013; 19:1411-21.

https://doi.org/10.1158/1078-0432.CCR-12-3433.

37. Carter JH, Douglass LE, Deddens JA, Colligan BM, Bhatt TR, Pemberton JO, Konicek S, Hom J, Marshall M, Graff JR. Pak-1 expression increases with progression of colorectal carcinomas to metastasis. Clin Cancer Res. 2004; 10:3448-56.

https://doi.org/10.1158/1078-0432.CCR-03-0210.

38. Ching YP, Leong VY, Lee MF, Xu HT, Jin DY, Ng IO. P21-activated protein kinase is overexpressed in hepatocellular carcinoma and enhances cancer metastasis involving c-Jun NH2-terminal kinase activation and paxillin phosphorylation. Cancer Res. 2007; 67:3601-08.

https://doi.org/10.1158/0008-5472.CAN-06-3994.

39. Goc A, Al-Azayzih A, Abdalla M, Al-Husein B, Kavuri S, Lee J, Moses K, Somanath PR. P21 activated kinase-1 (Pak1) promotes prostate tumor growth and microinvasion via inhibition of transforming growth factor $\beta$ expression and enhanced matrix metalloproteinase 9 secretion. J Biol Chem. 2013; 288:3025-35.

https://doi.org/10.1074/jbc.M112.424770.

40. Li X, Wen W, Liu K, Zhu F, Malakhova M, Peng C, Li T, Kim HG, Ma W, Cho YY, Bode AM, Dong Z, Dong Z. Phosphorylation of caspase-7 by $\mathrm{p} 21$-activated protein kinase (PAK) 2 inhibits chemotherapeutic drug-induced apoptosis of breast cancer cell lines. J Biol Chem. 2011; 286:22291-99. https://doi.org/10.1074/jbc.M111.236596.

41. Kaur R, Yuan X, Lu ML, Balk SP. Increased PAK6 expression in prostate cancer and identification of PAK6 associated proteins. Prostate. 2008; 68:1510-16.

https://doi.org/10.1002/pros.20787.

42. Zhang M, Siedow M, Saia G, Chakravarti A. Inhibition of p21-activated kinase 6 (PAK6) increases radiosensitivity of prostate cancer cells. Prostate. 2010; 70:807-16.

43. Rudolph J, Crawford JJ, Hoeflich KP, Wang W. Inhibitors of p21-activated kinases (PAKs). J Med Chem. 2015; 58:111-29. https://doi.org/10.1021/jm501613q.

44. Murray BW, Guo C, Piraino J, Westwick JK, Zhang C, Lamerdin J, Dagostino E, Knighton D, Loi CM, Zager M, Kraynov E, Popoff I, Christensen JG, et al. Small-molecule p21-activated kinase inhibitor PF-3758309 is a potent inhibitor of oncogenic signaling and tumor growth. Proc Natl Acad Sci USA. 2010; 107:9446-51.

https://doi.org/10.1073/pnas.0911863107.

45. Nicholas NS, Pipili A, Lesjak MS, Ameer-Beg SM, Geh JL, Healy C, MacKenzie Ross AD, Parsons M, Nestle FO, 
Lacy KE, Wells CM. PAK4 suppresses PDZ-RhoGEF activity to drive invadopodia maturation in melanoma cells. Oncotarget. 2016; 7:70881-97.

https://doi.org/10.18632/oncotarget.12282.

46. Ho H, Soto Hopkin A, Kapadia R, Vasudeva P, Schilling J, Ganesan AK. RhoJ modulates melanoma invasion by altering actin cytoskeletal dynamics. Pigment Cell Melanoma Res. 2013; 26:218-25.

https://doi.org/10.1111/pcmr.12058.

47. Ruiz R, Jahid S, Harris M, Marzese DM, Espitia F, Vasudeva P, Chen CF, de Feraudy S, Wu J, Gillen DL, Krasieva TB, Tromberg BJ, Pavan WJ, et al. The RhoJBAD signaling network: an Achilles' heel for BRAF mutant melanomas. PLoS Genet. 2017; 13:e1006913.

https://doi.org/10.1371/journal.pgen.1006913.

48. Ong CC, Jubb AM, Jakubiak D, Zhou W, Rudolph J, Haverty PM, Kowanetz M, Yan Y, Tremayne J, Lisle R, Harris AL, Friedman LS, Belvin M, et al. P21-activated kinase 1 (PAK1) as a therapeutic target in BRAF wild-type melanoma. J Natl Cancer Inst. 2013; 105:606-07.

https://doi.org/10.1093/jnci/djt054.

49. Lu H, Liu S, Zhang G, Wu B, Zhu Y, Frederick DT, Hu Y, Zhong W, Randell S, Sadek N, Zhang W, Chen G, Cheng $\mathrm{C}$, et al. PAK signalling drives acquired drug resistance to MAPK inhibitors in BRAF-mutant melanomas. Nature. 2017; 550:133-36.

50. Babagana M, Johnson S, Slabodkin H, Bshara W, Morrison C, Kandel ES. P21-activated kinase 1 regulates resistance to BRAF inhibition in human cancer cells. Mol Carcinog. 2017; 56:1515-25.

https://doi.org/10.1002/mc.22611.

51. Cerami E, Gao J, Dogrusoz U, Gross BE, Sumer SO, Aksoy BA, Jacobsen A, Byrne CJ, Heuer ML, Larsson E, Antipin Y, Reva B, Goldberg AP, et al. The cBio cancer genomics portal: an open platform for exploring multidimensional cancer genomics data. Cancer Discov. 2012; 2:401-04. https://doi.org/10.1158/2159-8290.CD-12-0095.

52. Gao J, Aksoy BA, Dogrusoz U, Dresdner G, Gross B, Sumer SO, Sun Y, Jacobsen A, Sinha R, Larsson E, Cerami E, Sander C, Schultz N. Integrative analysis of complex cancer genomics and clinical profiles using the cBioPortal. Sci Signal. 2013; 6:pl1.

https://doi.org/10.1126/scisignal.2004088.

53. Dan C, Nath N, Liberto M, Minden A. PAK5, a new brainspecific kinase, promotes neurite outgrowth in N1E-115 cells. Mol Cell Biol. 2002; 22:567-77.

https://doi.org/10.1128/MCB.22.2.567-577.2002.

54. Rennefahrt UE, Deacon SW, Parker SA, Devarajan K, Beeser A, Chernoff J, Knapp S, Turk BE, Peterson JR. Specificity profiling of Pak kinases allows identification of novel phosphorylation sites. J Biol Chem. 2007; 282:1566778. https://doi.org/10.1074/jbc.M700253200.

55. Szczepanowska J. Involvement of Rac/Cdc42/PAK pathway in cytoskeletal rearrangements. Acta Biochim Pol. 2009; 56:225-34.

56. Cotteret S, Jaffer ZM, Beeser A, Chernoff J. p21-Activated kinase 5 (Pak5) localizes to mitochondria and inhibits apoptosis by phosphorylating BAD. Mol Cell Biol. 2003; 23:5526-39.

https://doi.org/10.1128/MCB.23.16.5526-5539.2003.

57. Li RH, Hou XY, Yang CS, Liu WL, Tang JQ, Liu YQ, Jiang G. Temozolomide for Treating Malignant Melanoma. J Coll Physicians Surg Pak. 2015; 25: 680-8. https://doi.org/09.2015/JCPSP.680688.

58. Radu M, Semenova G, Kosoff R, Chernoff J. PAK signalling during the development and progression of cancer. Nat Rev Cancer. 2014; 14:13-25.

https://doi.org/10.1038/nrc3645.

59. Coles LC, Shaw PE. PAK1 primes MEK1 for phosphorylation by Raf-1 kinase during cross-cascade activation of the ERK pathway. Oncogene. 2002; 21:223644. https://doi.org/10.1038/sj.onc.1205302.

60. Frost JA, Steen H, Shapiro P, Lewis T, Ahn N, Shaw PE, Cobb MH. Cross-cascade activation of ERKs and ternary complex factors by Rho family proteins. EMBO J. 1997; 16:6426-38. https://doi.org/10.1093/emboj/16.21.6426.

61. Slack-Davis JK, Eblen ST, Zecevic M, Boerner SA, Tarcsafalvi A, Diaz HB, Marshall MS, Weber MJ, Parsons JT, Catling AD. PAK1 phosphorylation of MEK1 regulates fibronectin-stimulated MAPK activation. J Cell Biol. 2003; 162:281-91. https://doi.org/10.1083/jcb.200212141.

62. King AJ, Sun H, Diaz B, Barnard D, Miao W, Bagrodia S, Marshall MS. The protein kinase Pak3 positively regulates Raf-1 activity through phosphorylation of serine 338 . Nature. 1998; 396:180-83. https://doi.org/10.1038/24184.

63. Zang M, Hayne C, Luo Z. Interaction between active Pak1 and Raf-1 is necessary for phosphorylation and activation of Raf-1. J Biol Chem. 2002; 277:4395-405. https://doi.org/10.1074/jbc.M110000200.

64. Wu X, Carr HS, Dan I, Ruvolo PP, Frost JA. p21 activated kinase 5 activates Raf-1 and targets it to mitochondria. J Cell Biochem. 2008; 105:167-75.

https://doi.org/10.1002/jcb.21809.

65. Garraway LA, Widlund HR, Rubin MA, Getz G, Berger AJ, Ramaswamy S, Beroukhim R, Milner DA, Granter SR, Du J, Lee C, Wagner SN, Li C, et al. Integrative genomic analyses identify MITF as a lineage survival oncogene amplified in malignant melanoma. Nature. 2005; 436:11722. https://doi.org/10.1038/nature03664.

66. Smalley KS, Lioni M, Dalla Palma M, Xiao M, Desai B, Egyhazi S, Hansson J, Wu H, King AJ, Van Belle P, Elder DE, Flaherty KT, Herlyn M, Nathanson KL. Increased cyclin D1 expression can mediate BRAF inhibitor resistance in BRAF V600E-mutated melanomas. Mol Cancer Ther. 2008; 7:2876-83.

https://doi.org/10.1158/1535-7163.MCT-08-0431. 
67. Yadav V, Burke TF, Huber L, Van Horn RD, Zhang Y, Buchanan SG, Chan EM, Starling JJ, Beckmann RP, Peng SB. The CDK4/6 inhibitor LY2835219 overcomes vemurafenib resistance resulting from MAPK reactivation and cyclin D1 upregulation. Mol Cancer Ther. 2014; 13:2253-63.

https://doi.org/10.1158/1535-7163.MCT-14-0257.

68. Rodríguez CI, Setaluri V. Cyclic AMP (cAMP) signaling in melanocytes and melanoma. Arch Biochem Biophys. 2014; 563:22-27. https://doi.org/10.1016/j.abb.2014.07.003.

69. Chijiwa T, Mishima A, Hagiwara M, Sano M, Hayashi $\mathrm{K}$, Inoue $\mathrm{T}$, Naito $\mathrm{K}$, Toshioka $\mathrm{T}$, Hidaka H. Inhibition of forskolin-induced neurite outgrowth and protein phosphorylation by a newly synthesized selective inhibitor of cyclic AMP-dependent protein kinase, N-[2-(pbromocinnamylamino)ethyl]-5-isoquinolinesulfonamide (H-89), of PC12D pheochromocytoma cells. J Biol Chem. 1990; 265:5267-72.

70. Zehir A, Benayed R, Shah RH, Syed A, Middha S, Kim HR, Srinivasan P, Gao J, Chakravarty D, Devlin SM, Hellmann MD, Barron DA, Schram AM, et al. Mutational landscape of metastatic cancer revealed from prospective clinical sequencing of 10,000 patients. Nat Med. 2017; 23:703-13. https://doi.org/10.1038/nm.4333.

71. Cancer Genome Atlas N, and Cancer Genome Atlas Network. Comprehensive molecular characterization of human colon and rectal cancer. Nature. 2012; 487:330-37. https://doi.org/10.1038/nature11252.

72. Campbell JD, Alexandrov A, Kim J, Wala J, Berger AH, Pedamallu CS, Shukla SA, Guo G, Brooks AN, Murray BA, Imielinski M, Hu X, Ling S, et al, and Cancer Genome Atlas Research Network. Distinct patterns of somatic genome alterations in lung adenocarcinomas and squamous cell carcinomas. Nat Genet. 2016; 48:607-16.

https://doi.org/10.1038/ng.3564.

73. Kandoth C, Schultz N, Cherniack AD, Akbani R, Liu Y, Shen H, Robertson AG, Pashtan I, Shen R, Benz CC, Yau C, Laird PW, Ding L, et al, and Cancer Genome Atlas Research Network. Integrated genomic characterization of endometrial carcinoma. Nature. 2013; 497:67-73.

https://doi.org/10.1038/nature12113.

74. Eswaran J, Lee WH, Debreczeni JE, Filippakopoulos P, Turnbull A, Fedorov O, Deacon SW, Peterson JR, Knapp S. Crystal Structures of the p21-activated kinases PAK4, PAK5, and PAK6 reveal catalytic domain plasticity of active group II PAKs. Structure. 2007; 15:201-13. https://doi.org/10.1016/j.str.2007.01.001.

75. Callow MG, Zozulya S, Gishizky ML, Jallal B, Smeal T. PAK4 mediates morphological changes through the regulation of GEF-H1. J Cell Sci. 2005; 118:1861-72. https://doi.org/10.1242/jcs.02313.

76. Hornbeck PV, Zhang B, Murray B, Kornhauser JM, Latham V, Skrzypek E. PhosphoSitePlus, 2014: mutations, PTMs and recalibrations. Nucleic Acids Res. 2015; 43:D512-20. https://doi.org/10.1093/nar/gku1267.

77. Tabanifar B, Zhao Z, Manser E. PAK5 is auto-activated by a central domain that promotes kinase oligomerization. Biochem J. 2016; 473:1777-89. https://doi.org/10.1042/BCJ20160132.

78. Bachmann VA, Riml A, Huber RG, Baillie GS, Liedl KR, Valovka T, Stefan E. Reciprocal regulation of PKA and Rac signaling. Proc Natl Acad Sci USA. 2013; 110:8531-36. https://doi.org/10.1073/pnas.1215902110.

79. Park MH, Lee HS, Lee CS, You ST, Kim DJ, Park BH, Kang MJ, Heo WD, Shin EY, Schwartz MA, Kim EG. p21Activated kinase 4 promotes prostate cancer progression through CREB. Oncogene. 2013; 32:2475-82. https://doi.org/10.1038/onc.2012.255.

80. Yun CY, You ST, Kim JH, Chung JH, Han SB, Shin EY, Kim EG. p21-activated kinase 4 critically regulates melanogenesis via activation of the CREB/MITF and $\beta$-catenin/MITF pathways. J Invest Dermatol. 2015; 135:1385-94.

https://doi.org/10.1038/jid.2014.548.

81. Howe AK, Juliano RL. Regulation of anchorage-dependent signal transduction by protein kinase A and p21-activated kinase. Nat Cell Biol. 2000; 2:593-600.

https://doi.org/10.1038/35023536.

82. Fawdar S, Trotter EW, Li Y, Stephenson NL, Hanke F, Marusiak AA, Edwards ZC, Ientile S, Waszkowycz B, Miller CJ, Brognard J. Targeted genetic dependency screen facilitates identification of actionable mutations in FGFR4, MAP3K9, and PAK5 in lung cancer. Proc Natl Acad Sci USA. 2013; 110:12426-31. https://doi.org/10.1073/pnas.1305207110.

83. Meijering E, Dzyubachyk O, Smal I. Methods for cell and particle tracking. Methods Enzymol. 2012; 504:183-200. https://doi.org/10.1016/B978-0-12-391857-4.00009-4. 